\title{
The Design of Multimedia Interactive Courseware Based on FLASH
}

\author{
ZHU Xiaowei ${ }^{1, \text { a }}$ \\ ${ }^{1}$ Wuhan Polytechnic, Wuhan 430074, China \\ azhuxiaowei@126.com
}

Keywords: Interactive Courseware; FLASH; Multimedia

\begin{abstract}
As an advanced computer-assisted instruction teaching methods, its flexibility, intuitive, real-time, three-dimensional advantages, more and more by the majority of teachers and students of all ages. To make good use of computer-assisted instruction in this modern teaching methods, the key is to design and manufacture to meet the teaching requirements of multimedia courseware. Multimedia courseware is used to assist teachers in teaching tools, creative people based on their creativity, starting with general information on the classification of the organization, then the text, images, animation, audio, video and other media clips in both time and space integration, so that they blend and give them the interactive features to produce a variety of colorful multimedia educational software.
\end{abstract}

\section{Introduction}

With the level of information in modern society continues to improve, the rapid development of multimedia technology and network technology, community education industry put forward new demands. How the times, so that learners acquire more knowledge in a limited time, to train to adapt to social development, students with good knowledge and innovation ability, for particularly prominent in terms of vocational colleges [1-2]. The emergence of multimedia courseware to some extent, to solve this problem, it has a wealth of expression, good interaction and sharing. Teaching content through multimedia courseware can be difficult to show the vivid show to the students, a powerful tool to promote the modernization of teaching.

Adobe Flash, Macromedia American Company designed a two-dimensional animation software [3]. Usually includes Macromedia Flash, Flash for designing and editing documents, and Adobe Flash Player, for playing Flash document. It is in addition to the development of web animation production and web applications are widely used outside, in terms of interactive multimedia courseware are also many advantages .Flash supports multiple file formats leaders can be text, images, audio, video leaders and other documents, multimedia courseware provides a great convenience.

\section{The technology of Flash and theory analysis}

FLASH is an authoring tool that designers and developers can use it to create presentations, applications, and allows the user to interact with other content .FLASH can contain simple animations, video content, complex presentations and applications, and between them Nothing in between. Typically, each FLASH creative content are called applications, even though they may be just a very simple animation. You can also add pictures, sound, video and special effects, build rich media applications include FLASH program [4-6].

\section{A. FLASH features and advantages}

1. The composite good, strong interaction FLASH can put text, graphics, images, audio, video, animation and other information integrated in the FLASH animation clips and jumps action scenes can be used to achieve control, FLASH offers multiple interaction types, you can create a courseware with powerful interactive features, users can also enter tools and interactive courseware via mouse, keyboard and other powerful features to meet the needs of producers to provide. 
2. Powerful graphics, animation capabilities FIASH with strong graphics rendering capabilities, FLASH support frame by frame animation, shape gradient animation, animation and motion gradient mask animation .FLASH common formats can import images without distortion scaling, graphical vector format, zoom in or out will not affect the picture quality courseware, a big-screen playback.

3. The file size is small, fast running online FLASH on the network using the popular current streaming media technology, small files, transmission speed, suitable for network transmission and file sharing .FL gas SH achieve while downloading while playing, not because of the network cause inconsistent play, affecting playback. Students teaching resources through the network, web-based learning can be easily set up in the school LAN.

4. A strong compatibility, scripting languages FLASH animation format courseware may be other types of references, as can be inserted in PowerPoint courseware, FLASH courseware inserted in Dreamweaver web production using Action Script language capable of FLASH create colorful animation, and access to the database through the XML language to achieve contact with the web database FLASH for courseware to provide a broader application of space .FLASH courseware but also through the "Publish Settings", select "html "option, the system automatically generates a namesake of" html "page file. Thus, FLASH has good prospects in the course of the production network.

\section{B. The Type of Animation}

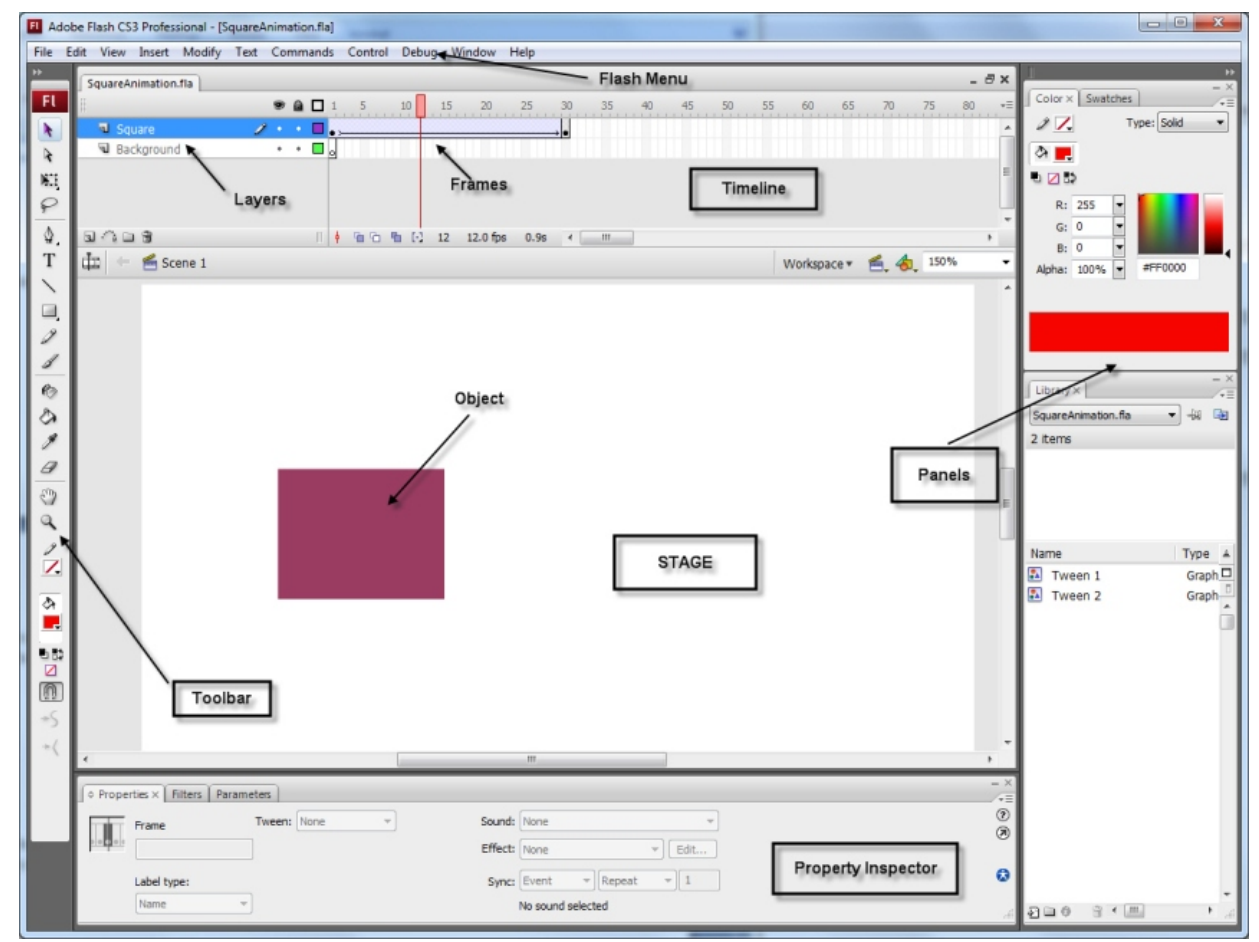

Figure 1. Flash working interface

Flash animation is divided into three types: tween animation, frame by frame animation, scripted animation. Tween animation means to draw only the start key frame and end key frame, the middle of the transition frames are designed by FLASH software, tween animation includes two types: motion tween animation and shape tween animation. Frame by frame animation: frame by frame animation is a traditional production method. In traditional animation, each frame is hand-painted. Script animation: Flash owns built-in script language Action Script. Action Script can easily create animation which is difficult to accomplish or simply unable to complete by above two animated types. 540 M. Su 69.3.2 The Working Interface of Flash The working interface of Flash includes menu bar, toolbar, control panel, edit area. To create Flash multimedia courseware, we must first create a new Flash animation file, and then set the file attributes and save the file courseware. When we finish Flash courseware, we should create running file which is freed from the Flash environment and used in teaching. Flash can work output for a variety of file formats, 
such as the SWF, HTML, and the EXE. We can select a format to output as needed. In order to create a beautiful interface, combining static and dynamic, sound and shape, convenient interact of multimedia courseware, we should proficient grasp the basic operation of Flash CS3, such as layers, frames and key frame operation, which is shown in Figure 1.

\section{Flash multimedia courseware development process}

Flash-based multimedia courseware in the development, we can treat it as a project, the project consists of multiple process components. An excellent courseware content requires teachers teaching science planning and design, so as to improve the usefulness courseware, play an active role in teaching [7]. The Flash multimedia courseware development process is show in figure 2.

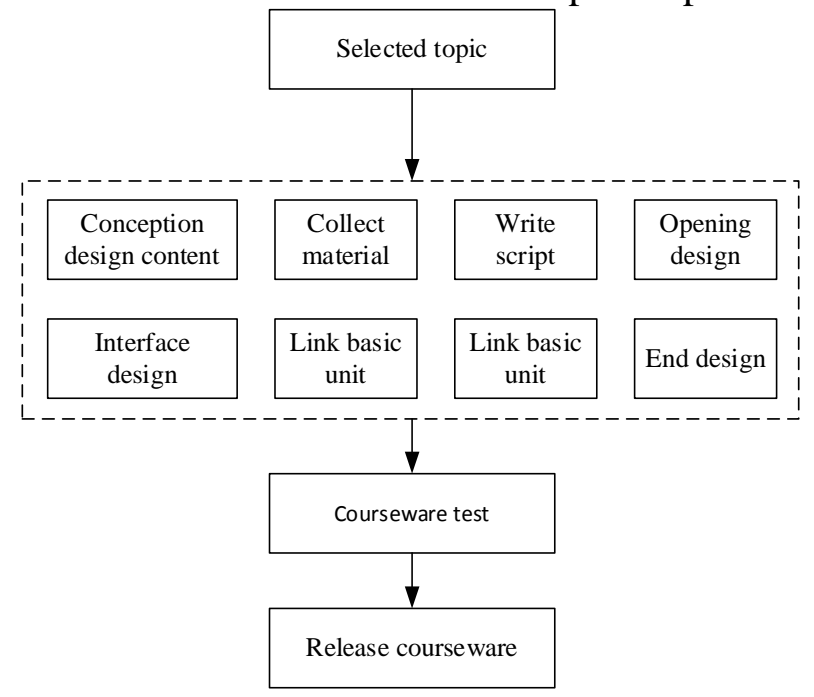

Figure 2.The Flash multimedia courseware development process

Selected topic. Multimedia courseware aided teaching purpose is to break the existing mode of teaching, the teacher dictating and writing on the blackboard into a courseware, a more vivid way to show them, to improve students' interest in learning, thus improving the quality of teaching. But it is worth noting is that courseware needs most is scientific and practical, the only way to play the advantages of multimedia technology, better teaching results. Issue is particularly important in the selection of multimedia courseware in Flash. Courseware design issues should be preceded by a clear content, and the content of the required subjects for analysis. Sometimes the subject content does not require Flash multimedia courseware, once the use of courseware will bother to make the design courseware became futile work. In Flash multimedia courseware design but also on the subject of feasibility analysis, see the topic needs to avoid time-consuming and difficult to achieve long phenomenon, the only way to make the courseware to play their own value, improve classroom efficiency.

Technology use. Insert the appropriate graphics, audio or video and other media files in Flash multimedia courseware, courseware can become vivid. For example, in Flash software, you can add mp3, wav and other audio files, in addition, to create a sound object in the action-script can also be more flexible control of the sound, so Flash multimedia courseware can be enriched by a lot. The use of layers is also a good way to increase the Flash multimedia courseware. Layer can reflect the spatial characteristics of objects, object, background, motion, etc. placed on different layers, seemingly independent of each other but in reality closely linked to the future of editing maintenance is extremely beneficial. Courseware when using full screen better, users can opt out at any time classroom, so that teachers provide a convenience. It is noteworthy that in the use of multimedia courseware, if a large number of graphic images into the courseware, it is very likely due to improper use and dispersed the students' attention to cause side effects.

Courseware test. In the design of Flash multimedia courseware for too long because of time-consuming, so inevitably there will be omissions, some errors in the production process is difficult to find, but if you run immediately after production is complete, will be in the classroom 
problems, and the expected effect of the opposite class, then you need to make at the end of the Flash multimedia courseware for testing. People often have such a misunderstanding, do their own thing is hard to find the problem, then it is best to ask other teachers to Flash multimedia courseware for testing, but can also listen to others to evaluate the courseware, so early detection and timely corrections.

\section{FLASH based interactive multimedia courseware application}

Multimedia refers to human interaction and a variety of media, information about your computer interact, giving users a more efficient means of control and use of information. Multimedia show at the same time teaching content by entering text, click the button, buttons, etc. to achieve dialogue and computers for students to integrate into the learning environment provided, which were involved in learning, rather than just passively receive. Learners through a variety of mouse and keyboard interaction, increasing the uncertainty of unknown content and inspire learners to explore enthusiasm. Therefore, interactive multimedia courseware design will directly affect the merits of learning learners. Only scientific, rational and effective interaction design can fully mobilize the enthusiasm of the learners to dedicate themselves to the study, the initiative to explore, to mobilize enthusiasm for learning, improving the quality and efficiency of learning. The interactive multimedia courseware application based on FLASH is show in figure 3.

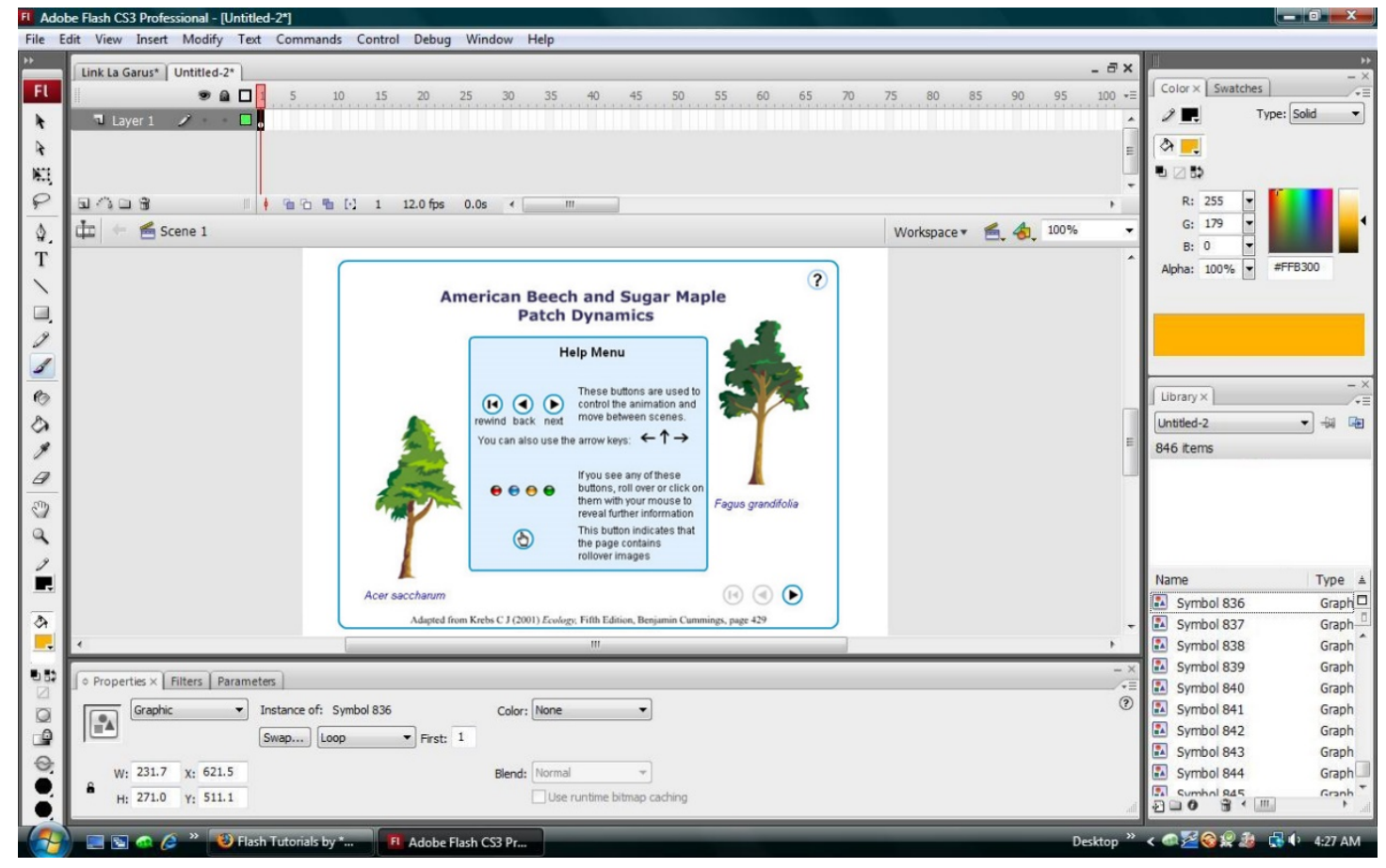

Figure 3. Research of Flash Interactive Features in Courseware Design

Learners and interactive courseware interface. Learners for interactive media interface level directly affects the content of the course of study, a good man-machine interface can successfully guide the learner to start teaching content, teaching quality has a great role in promoting. How will teaching content on the computer to show flexibility and to highlight teaching points, breaking the difficulty of teaching, students and other abilities and qualities.

Learners and interactive learning content. Unlike interactive learning content interactive human-machine interface, and can be expressed in the mouse, keyboard and other intuitive way. Content interaction is implicit, are invisible interactive content and instructional design strategies reflected in FLASH courseware, teaching objectives and the like.

The interaction between teachers and learners. In the learning process, the learner through interactive human-machine interface interaction and learning content can basically complete the 
teaching content. But for some complex, uncertain and difficult to understand the knowledge, self-learning alone, to think for themselves is difficult to solve.

\section{Conclusion}

Flash multimedia courseware development requires a combination of knowledge and technology, when a beautiful interface of Flash multimedia courseware can not only during the instructional design, prompting the teacher to grasp the overall teaching plan, assist classroom teachers, but also can promote students' self-initiative and can potentially enhance students' aesthetic taste. Therefore, Flash multimedia courseware application is bound to be more widely applied to teaching. With the continuous development of science and technology, more modern teaching model applied to teaching, flash virtue of its interactive, small-capacity, the advantages of vivid colors, having a rich appeal. In this paper, combined with Flash multimedia courseware features, a simple analysis of its development process.

\section{Reference}

[1] Gao Z, Wang C. Constructing virtual hydraulic circuits using Flash[J]. Computer Applications in Engineering Education, 2010, 18(2): 356-374.

[2] Guangzhong L, Junying L, Dan Q, et al. Applied research on Flash technology in multimedia teaching of medical electronics [J][J]. China Medical Education Technology, 2009, 5: 013.

[3] Abdollah N, Ahmad W F W, Akhir E A P. Multimedia Design and Development in" Komputer Saya'Courseware for Slow Learners[C]//Computer Research and Development, 2010 Second International Conference on. IEEE, 2010: 354-358.

[4] Çetin A. 3D Web based learning of medical equipments employed in intensive care units[J]. Journal of Medical Systems, 2012, 36(1): 167-174.

[5] Aziz N, Roseli N H M, Eshak E S, et al. Assistive Courseware for the visually impaired based on theory of multiple intelligence[C]//Proceedings of Knowledge Management International Conference. 2010.

[6] Al-Rawi W T, Jacobs R, Hassan B A, et al. Evaluation of web-based instruction for anatomical interpretation in maxillofacial cone beam computed tomography[J]. Evaluation, 2014, 36(8).

[7] Zaini Z H, Ahmad W F W. Application of design and learning theories in multimedia courseware development, 'Li2D’[C]//National Postgraduate Conference (NPC), 2011. IEEE, 2011: $1-5$. 